\title{
Audio-Visual Aids to Teaching Videotape Reviews
}

Long-Term Treatment of Parkinson's Disease-Where do we go from Here? (UK, 1985, 18 mins)

A clinical demonstration of the effectiveness of treatment by levodopa in relieving the signs and symptoms of Parkinson's Disease forms an arresting opening to this comprehensive tape, which goes on to deal in detail with the prognosis, and progress under treatment, of this disease. There is an authoritative exposition of the present problems of dosage and many aspects of this tape will be of special value in up-dating psychiatric teaching.

Although there is an element of the 'talking heads' syndrome, the clinical recordings make for compelling viewing and the graphic illustrations are particularly good. A very competent production that won a gold award in the 1985 BMA competition.

Production: Little King Productions Ltd. Medical Participants: Andrew Lee and Richard Hardie (University College Hospital). Distribution: Roche Products Ltd, PO Box 8, Welwyn Garden City, Herts Al7 3AY. Format: VHS.

Tuberose Sclerosis (UK, 1985, 26 mins)

After a brief introduction outlining the history, prevalence, genetics and clinical diagnosis of the condition, this tape gives details of four patients. One is not mentally handicapped but all are under 16 and excellent histories are given by the mothers in each case.

The clinical illustrations are superb and, combined with the first-class commentary, they offer a most valuable introduction to early diagnosis and control of this condition, which occurs in 1:10,000 people. Although the prime viewers will be paediatricians and general practitioners, trainee psychiatrists would benefit from seeing it, aug mented by comments on the management of adults, the alleviation of parental stress, and the genetic risk in other, mentally normal, siblings.

The tape deservedly won a bronze award in a recent BMA/BLAT competition. Further supplementary information is available from the Tuberose Sclerosis Association of Great Britain.

Written by: Ann Hunt and Jenny Dennis with advice from Richard Lindenbaum, Department of Medical Genetics, University of Oxford. Production: Department of Medical Illustration, University of Oxford. Distribution: Tuberose Sclerosis Association, Martell Mount, Holywell Road, Malvern Wells, Worcs WR14 4LF. Format: VHS. Free loan for teaching purposes.

\section{Could it be Parkinson's? - The Clues are There \\ (UK, 1985, 13 mins)}

This tape illustrates the early signs of Parkinson's Disease and shows tests that can be performed in the developing stages. The differential diagnosis is also illustrated and discussed.

This is a very competent and professional production, with an excellent commentary, well recorded. The interviews with the medical participants are nicely balanced, and the clarity and comprehensive range of the clinical illustrations will be particularly appreciated.

There is a valuable demonstration of early tests, and psychiatric tutors will find many aspects of this agreeably concise production to have value in their teaching. The tape has pace and style and well deserved its bronze award in the recent BMA video competition.

Production: Wessex Film and Video Productions. Medical Participants: Andrew Lees (Consultant Neurologist), Kathi Murphy and William Walker (general practitioners). Distribution: Roche Products Ltd, PO Box 8, Welwyn Garden City, Herts AL7 3AY. Format: VHS.

\section{Recognising, Describing and Managing Epileptic Fits (UK, 1983, 30 mins)}

This is apparently programme number one of a series and it is primarily aimed at lay audiences. It is a very professional production with excellent graphics and very good sound. The editing is first-class, although the picture quality is variable at times. The commentary is clear and informative.

In spite of its main intent it contains most valuable teaching material suitable for senior medical students, general practitioners and psychiatric trainees, especially if the rather elementary introduction is skipped. Well over half the tape consists of outstanding clinical illustrations of, for example, absences, myoclonic jerks, tonic fits, tonic-iatonic and tonic-clonic fits. It is especially valuable on the subject of focal simple partial and complex partial fits.

This production is an object lesson in the appropriate, and classical, use of the audio-visual media for teaching purposes. Talking heads are kept to a minimum and it gets on with the job with verve and style. Thoroughly recommended. 
Production: National Society for Epilepsy. Medical Adviser: Jolyn Oxley. Distribution and purchase: Chalfont Centre for Epilepsy, Chalfont St Peter, Gerrards Cross, Bucks. (Teaching package $\mathbf{6 6 0}$, including postage; all formats). Hire: Concord Films Council, 201 Felixstowe Road, Ipswich.

T. L. Pilkington University of Leeds (Convenor, Audio-Visual Group)

The Last Taboo: Mental Handicap and Death (UK, 1986, 22 mins)

This video programme was written, directed and produced by Dr Lester Sireling and Dr Sheila Hollins, Section of the Psychiatry of Mental Handicap, St George's Hospital Medical School, London. It shows two people with mental handicap in a bereavement situation, and demonstrates how their changed behaviour is related to their grief. It emphasises the often disregarded fact that people with intellectual impairment have feelings just like everyone else, and in life events of this kind due regard must be paid to helping them through their crises. It goes on to show this being done.

'The Last Taboo', claim the authors, "provides a valuable reminder to all who work with people with mental handicaps that lack of speech and awkward manner do not preclude emotions as sensitive as in the rest of us. Families and professionals can easily misinterpret grief reactions. The film shows how, once there is an understanding of grief, reactions become understandable and attitudes change." The film certainly achieves this aim.

Unfortunately it is technically not a very good film; the colour seems not to be properly balanced, the sound recording is spoiled by considerable background noise and there have been problems with editing. I think it a great pity that such splendid content is impaired by irritating technicalities.*

Available from the Department of Psychiatry, St George's Hospital Medical School, London SW17 ORE, VHS or U-matic, for $£ 25.00$, including postage.

G. E. Roberts University Hospital, Nottingham

*It is understood that this tape has now been re-recorded.

\section{Forthcoming Events}

A two day Introductory Course in Family Psychiatry for Trainee Psychiatrists will be held on 11 and 12 June 1987 at the Institute of Family Psychiatry, The Ipswich Hospital. Programmes and application forms: The Secretary, The Institute of Family Psychiatry, The Ipswich Hospital, 23 Henley Road, Ipswich IP1 3TF (telephone 047321481 ).

The Annual Meeting of Teachers of Child and Adolescent Psychiatry will take place in Manchester on 5 June 1987. Further information: Dr J. Eminson, Jesson House, Royal Manchester Children's Hospital, Manchester Road, Pendlebury, Manchester M27 IFG (telephone 061793 8145).

Open Meetings on Therapeutic Work with the Mentally Handicapped are currently being held on the first Friday of each month from 1.00-2.20 p.m. at the Tavistock Clinic. Formal presentations of papers by experts in the field of mental handicap will be made, as well as discussions of therapeutic work in progress and other related topics of interest. Attendance is welcome from anyone working in this field. Information: Valerie Sinason, Child and Family Department, The Tavistock Clinic or Jon Stokes, Adult Department, The Tavistock Clinic, Tavistock Centre, 120 Belsize Lane, London NW3 5BA (telephone 014357111 ).
The College Group of Liaison Psychiatry will be holding a conference on 18-20 September 1987 at the St Edmond Hall, Oxford. There will be plenary sessions on major issues in liaison for general and child psychiatrists and also poster sessions and opportunities to discuss current clinical developments, research and teaching. It is expected that there will be enough accommodation for members to bring guests. The provisional programme will be available early in 1987. Further information: Deborah Hart, Royal College of Psychiatrists, 17 Belgrave Square, London SWIX 8PG.

Nottingham Mental Illness Unit in conjunction with members of the West Midlands Institute of Psychotherapy will be presenting a Symposium on Creativity and Psychotherapy at Mapperley Hospital on 7 March 1987 (10 a.m.-5 p.m.). Presenters will include Dr Anthony Storr, Dr Charles Rycroft, Mrs Shirley Wheeley, Dr Gerald Dickens and Dr Martin Davies. Chairpersons: Dr Mark Aveline and Dr John Harrington. Fee $\mathbf{E 1 8}$ (includes lunch). A selection of books will be available for purchase relating to the theme. Details: Mr Maurice Furlong, Mapperley Hospital, Porchester Road, Nottingham NG3 6AA (telephone 0602 608144, extension 379/210). 